\title{
Comparative Study of Degradation of Reactive Dyes and Decolorization and Detoxification in Aqueous Solution Applying DyP Peroxidases Isolated from Saccharomonospora viridis (SviDyP) and Thermobifida fusca (TfuDyp)
}

\author{
Carolline Schreiber, ${ }^{a}$ Franklin M. F. de Souza, ${ }^{a}$ Paulo C. de Jesus, ${ }^{\circ b}$ Eduardo Zapp ${ }^{a}$ and \\ Patrícia B. Brondani ${ }^{\oplus *, a}$ \\ ${ }^{a}$ Departamento de Ciências Exatas e Educação, Universidade Federal de Santa Catarina, \\ Rua João Pessoa, 2750, 89036-256 Blumenau-SC, Brazil \\ ${ }^{b}$ Departamento de Química, Universidade Regional de Blumenau, \\ Rua Antônio da Veiga, 140, 89019-917 Blumenau-SC, Brazil
}

\begin{abstract}
The wastewater that originates from the widespread usage of synthetic dyes in the industry have become a severe environmental problem. Several efforts have been made to develop new types of treatment which are capable of performing the degradation of the dyes from the environment. Within this scope, much attention has been drawn to enzymatic approaches, mainly the ones applying oxidative enzymes, such as peroxidases. A recently discovered superfamily of peroxidases, the so called dye-decolorizing peroxidases (DyPs) is a promising alternative to further improve the efficiency of these processes. In this work, two of these peroxidases (Saccharomonospora viridis (SviDyP) and Thermobifida fusca (TfuDyp)) were tested together with twelve different reactive dyes in order to evaluate the efficiency of degradation and decolorization, leading to good results. When applying the $S v i$ DyP enzyme in experiments carried out for $12 \mathrm{~h}$ in $\mathrm{pH} 3$, the degradation efficiencies were above $80 \%$ for some dyes. The biodegradation efficiency data and cyclic voltammograms were recorded to obtain the redox potential of the chosen dyes and enzymes. In addition, an electrochemical biosensor was used to gauge the genotoxicity of the generated bioproducts. This analysis showed that bioproducts from dye degradation mostly present a lower degree of genotoxicity when compared to the control reactions.
\end{abstract}

Keywords: dye degradation, DyP peroxidases, electrochemical genotoxicity assay

\section{Introduction}

Synthetic dyes, especially the ones from the reactive class, are extensively used in industry. ${ }^{1,2}$ The wastewater originating from both dye production and their use, during which significant losses can occur, has become a major environmental problem. ${ }^{1,3}$ More than that, synthetic dyes are characterized by poor biodegradability and are usually unaffected by conventional wastewater treatment systems, due to their high stability. ${ }^{3}$ The presence of dyes in rivers and oceans can prevent the penetration of light and the transfer of oxygen, deeply affecting the aquatic life. ${ }^{1,4}$ These compounds are recalcitrant in nature, and some of them are also well established to be potentially carcinogenic and mutagenic as well as genotoxic. ${ }^{1}$

Research efforts have been devoted to developing lowcost and eco-friendly treatments capable of reducing and

*e-mail: patyqmc@gmail.com even eliminating synthetic dyes from the environment. Several physicochemical procedures like adsorption, coagulation, and reverse osmosis, in addition to other biological based methodologies, are commonly used for effluent treatment. These methods, however, have shortcomings: typically, pollutants are not completely degraded, but only concentrated or transferred from one phase to another and not eliminated from the environment. ${ }^{5}$ In addition to their low effectiveness, most of these treatments also possess a high associated cost. ${ }^{2}$

Among the most promising methodologies to improve on this scenario, enzymatic approaches have attracted much interest in the decolorization and/or degradation of industrially important dyes from wastewater.

Enzymes can operate over a broad dye concentration range and are able to act on specific recalcitrant pollutants, removing them by precipitation or transformation to other products. They might also change the characteristics of a given waste to render it more amenable for further 
treatment. Even though, enzymes can have low activity under certain conditions of $\mathrm{pH}$ and temperature, in general, the above mentioned processes are efficient and selective when compared to chemical catalysts due to higher reaction rates, milder reaction conditions and greater selectivity. The eventual inhibition process by toxic substances is minimum in enzymatic treatment. ${ }^{6,7}$

Oxidative enzymes, such as laccases and peroxidases, are commonly applied in the decolorization and degradation of dyes. ${ }^{1,7}$ Laccases, for instance, are able to oxidize a wide range of phenolic substrates without the presence of additional cofactors, generating less toxic products. ${ }^{8}$ As another example, the horseradish peroxidase is widely used in dye degradation and is known as a versatile enzyme, which is able to perform the degradation and precipitation of important industrial azo dyes, when in the presence of hydrogen peroxide. , $7,7,10^{-10}$

A superfamily of dye-decolorizing peroxidases (DyPs) has been recently described. This superfamily is mostly present in bacteria, and can be subdivided into four types, A, $\mathrm{B}, \mathrm{C}$ and D, based on their primary sequences. ${ }^{11}$ Originally, they were named after the activity towards decolorization of dyes and they are typically identified by their activity on anthraquinone derivatives. ${ }^{12}$ Although their physiological substrates are unknown, they have been demonstrated to carry out lignin and dye degradation in the last two decades. ${ }^{13}$ These bacterial and fungal heme peroxidases have attractive catalytic properties demonstrating activity for a wide range of substrates using hydrogen peroxide as an electron acceptor. ${ }^{14}$ This new superfamily is capable of catalyzing not only the oxidation of anthraquinone, but of a wide range of dyes, such as azo derivatives, that usually have high redox potentials. ${ }^{15}$

A relatively new thermostable DyP-type peroxidase isolated from Saccharomonospora viridis (SviDyP) has attracted attention due to its interesting properties for the use in the pulp and paper industries and in the degradation of some dyes. ${ }^{16}$ Another robust DyP peroxidase is the one from Thermobifida fusca (TfuDyP). The activity of this enzyme towards several reactive dyes and in the enantioselective sulfoxidation of organic compounds has already been described. ${ }^{12}$ These studies open a perspective for the application of $S v i \mathrm{DyP}$ and $T f u \mathrm{DyP}$ in the remediation of wastewater containing reactive dyes.

Many of these new methodologies, including the biocatalytic ones, can be efficient in decolorization/ degradation of dyes. In order to gauge this efficiency, the level of toxicity in the treated wastewater must be evaluated. It is known, for example, that the reduction of the azo group generates aromatic amines, known to be toxic and/ or mutagenic. This is still the case when the reduction is carried out through reactions employing enzymes and/or microorganisms. Therefore, subsequent treatments need to be applied in order to produce only non-hazardous substances in the process. ${ }^{17,18}$

The analysis of potentially toxic molecules should be applied to characterize different types of possibly contaminated samples, ${ }^{19}$ and contributes to different segments of society, such as industry, health, waste treatment, water treatment, among others. ${ }^{20}$ Several methods for detecting dyes, mainly azo dyes, have been reported in the literature. ${ }^{21-26}$ The majority of these methodologies, however, often require long analysis times, qualified human resources and expensive equipment. ${ }^{20,21}$ Electrochemical sensors represent an attractive and viable alternative for wastewater analysis, presenting advantages such as simplicity of operation, short analysis time, high sensitivity and lower costs when compared to other analytical methodologies. ${ }^{27,28}$ Among the different types of electrochemical sensors, we can highlight those that operate based on: voltametric, ${ }^{29}$ potentiometric, ${ }^{30}$ and electrochemical impedance spectroscopic (EIS) techniques. ${ }^{31}$ The combination of electrochemical techniques with deoxyribonucleic acid (DNA) as a biomolecular component, generating devices called genosensors, offers a useful platform for monitoring DNA damage and to perform studies of the DNA interactions with various genotoxic agents. ${ }^{28,32}$ Several nanomaterials (e.g., nanorods, nanotubes, metal nanoparticles and graphene) can be easily applied in electrochemical sensing platforms, ${ }^{33-35}$ conferring advantages to these devices such as high-performance electrochemical sensitivity, selectivity, simplicity, robustness and long-term stability. ${ }^{20,36}$

Besides some research applying the DyP-type peroxidases searching for substrate acceptance, there are not many works exploring the reactions coupled with tests of the toxicity in the wastewater after the optimized bioremediation process. The main goal of this work was to test the decolorization and degradation of different reactive dyes applying two of these new peroxidases (SviDyP and $T f u \mathrm{DyP})$. In order to evaluate the efficiency and to better understand these processes, cyclic voltammograms were recorded with the chosen dyes and enzymes. An electrochemical system was used in order to gauge the genotoxicity of the generated bioproducts.

\section{Experimental}

\section{Enzymes, chemicals and reagents}

The selected dyes, named Reactive Green 19 (RG19), Reactive Blue 182 (RB182), Reactive Red 195 (RR195), 
Reactive Red 120 (RR120), Reactive Black 5 (RB5), Reactive Blue 21 (RB21), Reactive Blue 198 (RB 198), Reactive Yellow 15 (RY15), Reactive Yellow 42 (RY42), Reactive Blue 171 (RB171), Reactive Yellow 84 (RY84) and Reactive Yellow 176 (RY176), were kindly donated by Têxtil fio Malhas Ltda. from Blumenau-SC, Brazil. Hydrogen peroxide and all the other chemicals were obtained from Vetec, São Paulo, Brazil, and used without previous treatment. The DNA was obtained from SigmaAldrich, Saint Louis, USA. The enzymes (SviDyP and $T f u$ DyP) were kindly donated by Prof Dr Marco W. Fraaije from University of Groningen, Groningen, The Netherlands.

\section{Activity assays}

The activity of the enzymes towards the reactive dyes was measured spectrophotometrically (Shimadzu UV-1800, Kyoto, Japan). The reaction mixtures were prepared with $50 \mathrm{mmol} \mathrm{L}^{-1}$ of the dye and $100 \mathrm{mmol} \mathrm{L}^{-1} \mathrm{H}_{2} \mathrm{O}_{2}$. The total volume of $3 \mathrm{~mL}$ was completed by adding $50 \mathrm{mmol} \mathrm{L}^{-1}$ phosphate buffer $\mathrm{pH} 3.0,4.0$ or 5.0 or $50 \mathrm{mmol} \mathrm{L}^{-1}$ tris- $\mathrm{HCl}$. The enzyme was added to start the reaction $\left(300 \mathrm{nmol} \mathrm{L}^{-1}\right.$ of the purified enzyme). The initial rate of oxidation was measured at the corresponding maximum wavelength $\left(\lambda_{\max }\right)$ for each dye.

\section{Degradation reactions}

Reaction mixtures contained $50 \mathrm{mmol} \mathrm{L}^{-1}$ of the dye and $100 \mathrm{mmol} \mathrm{L}^{-1} \mathrm{H}_{2} \mathrm{O}_{2}$. The total volume of $3 \mathrm{~mL}$ was completed by adding $50 \mathrm{mmol} \mathrm{L}^{-1}$ citrate buffer $(\mathrm{pH} 3.0$, 4.0 or 5.0 ) or $50 \mathrm{mmol} \mathrm{L}^{-1}$ tris- $\mathrm{HCl}$ (pH 7.0). The enzyme was added to start the reaction $\left(300 \mathrm{nmol} \mathrm{L}^{-1}\right.$ of the purified enzyme). Reactions were subsequently incubated from $30 \mathrm{~min}$ to $2 \mathrm{~h}$ at $25^{\circ} \mathrm{C}$.

For the $12 \mathrm{~h}$ experiments, the reactions mixture started with $300 \mathrm{nmol} \mathrm{L}^{-1}$ of enzyme and $100 \mathrm{mmol} \mathrm{L}^{-1}$ of $\mathrm{H}_{2} \mathrm{O}_{2}$. At $4 \mathrm{~h}$ intervals and over a total reaction time of $12 \mathrm{~h}$, additional enzyme $\left(0.05 \mathrm{nmol} \mathrm{L}^{-1}\right)$ and $\mathrm{H}_{2} \mathrm{O}_{2}\left(0.2 \mathrm{mmol} \mathrm{L}^{-1}\right)$ were added to the reaction mixture. The visual observation of the decolorization was possible in this case.

After the total time, the spectra between 300 and $800 \mathrm{~nm}$ were taken to estimate the efficiency of degradation (E), which was calculated using the equation 1 , where $\mathrm{Abs}_{\text {initial }}$ and $\mathrm{Abs}_{\text {final }}$ denote, respectively, the initial absorbance and the absorbance after degradation.

$\mathrm{E}(\%)=\left[\left(\mathrm{Abs}_{\text {initial }}-\mathrm{Abs}_{\text {final }}\right) / \mathrm{Abs}_{\text {initial }}\right] \times 100$

Control reactions without enzyme and with enzyme and without $\mathrm{H}_{2} \mathrm{O}_{2}$ were included. All the reactions were conducted in triplicate and the $\mathrm{E}(\%)$ values presented are the average based on that.

\section{Cyclic voltammetry of the reactive dyes and enzymes}

The measurements were performed using a Dropsens Stat 400 (Metrohm-DropSens, Oviedo, Spain) potentiostat/ galvanostat, the supporting electrolyte was $0.1 \mathrm{~mol} \mathrm{~L}^{-1}$ Britton-Robbinson buffer solution (BRBS, $\mathrm{pH}$ values were adjusted to: 3.0, 5.0, 7.0, 9.0 and 11.0), composed of $0.04 \mathrm{~mol} \mathrm{~L}^{-1}$ of each: acetic acid, phosphoric acid and boric acid. Unless otherwise stated, every dye was tested in a concentration of $5.00 \times 10^{-3} \mathrm{~mol} \mathrm{~L}^{-1}$. Enzymes were evaluated in supporting electrolyte at $\mathrm{pH} 3.0$ and 7.0. The voltammetric assays were performed in a three electrodes electrochemical cell, with a pyrolytic carbon electrode (PCE) as working electrode, an $\mathrm{Ag} / \mathrm{AgCl}$ electrode as reference and a platinum wire as the counter electrode. Dye behavior was evaluated with potential sweep potential from -1.0 to $+1.0 \mathrm{~V} v$ s. $\mathrm{Ag} / \mathrm{AgCl}$, and return from $+1.0 \mathrm{~V}$ to $-1.0 \mathrm{~V} v s$. $\mathrm{Ag} / \mathrm{AgCl}$ at scan rate of $0.05 \mathrm{~V} \mathrm{~s}^{-1}$.

\section{Genotoxicity assay}

\section{Genotoxicity electrochemical sensor}

The assay was performed by assembling an electrochemical genosensor obtained by modifying a PCE surface with the adsorption of a gold nanoparticles layer, followed by a DNA layer and the redox probe layer. The Reactive Black 5 was applied as probe, because it was one of the most stable and least water soluble among the tested dyes.

The kappa carrageenan stabilized gold nanoparticles (AuNp-KC), with an average diameter of $13.5 \mathrm{~nm}$, were synthesized via chemical reduction methods with sodium borohydride, and then a $4.0 \mu \mathrm{L}$ aliquot was dripped with a micropipette onto a surface of a previously cleaned PCE and left to dry at vacuum for $10 \mathrm{~min}$. Then, the electrode was washed carefully, and the DNA aliquot ( $4.0 \mu \mathrm{L}$ of $0.2 \mathrm{mg} \mathrm{mL}^{-1}$ ) and the redox probe $(4.0 \mu \mathrm{L}$ of $\left.5 \times 10^{-3} \mathrm{~mol} \mathrm{~L}^{-1}\right)$ were assembled the same way.

The assay was performed by evaluating the variation of the redox probe electroanalytical signal after interaction with the samples (10 min incubation), which was compared with the before interaction signal (base peak). The redox probe signal was measure utilizing square wave voltammetry (SWV) as the sensing method, the potential measurements were recorded versus $\mathrm{Ag} / \mathrm{AgCl}$, frequency of $90 \mathrm{~Hz}$, amplitude potential of $60 \mathrm{mV}$ and increment potential of $5 \mathrm{mV}$. 


\section{Genotoxicity spectrophotometric assay}

The spectrophotometric assays of the samples were performed on a Shimadzu UV-Vis spectrophotometer (model UV-1800, Kyoto, Japan) using $1.0 \mathrm{~mL}$ quartz cells with $1.0 \mathrm{~cm}$ optical pathway. Absorbance measurements were obtained in the range $200-600 \mathrm{~nm}$ in a buffered solution (BRBS pH 7.0). The interaction between $250 \mu \mathrm{L}$ of DNA $\left(0.04 \mathrm{mg} \mathrm{mL}^{-1}\right)$ and each of the byproduct solutions was observed by recording the spectra after adding $250 \mu \mathrm{L}$ of the sample (test I). Additionally, spectra of the interaction between DNA $(250 \mu \mathrm{L})$ and the redox probe $(250 \mu \mathrm{L}$ of $100 \mathrm{mmol} \mathrm{L}^{-1}$ ) was recorded (test II). To simulate the electrochemical system, the interaction between DNA, redox probe and samples was recorded by adding $250 \mu \mathrm{L}$ of DNA to $125 \mu \mathrm{L}$ of each, the redox probe $(100 \mathrm{mM})$ and sample (test III).

\section{Results and Discussion}

\section{Degradation reactions}

In order to investigate the activity of $S v i \mathrm{DyP}$ and $T f u$ DyP in the presence of the selected reactive dyes applying different $\mathrm{pH}$ systems $(\mathrm{pH} \mathrm{3,4,5}$ or 7) the initial activity $\left(\mathrm{k}_{\mathrm{obs}}\right)$ was measured. The activity assays were performed observing the $\lambda_{\max }$ for each dye in the respective $\mathrm{pH}$. After the activity was verified, the degradation reactions could be set.
The investigation started by measuring the amount of degraded dye in 30 min reactions applying the DyP enzymes and the selected dyes in different $\mathrm{pH}$ systems

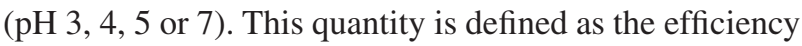
of degradation $\mathrm{E}(\%)$. The initial tests were performed applying eight different dyes. The best results in terms of $\mathrm{E}(\%)$ where observed when working with $\mathrm{pH} 3$ and 7 . These results are presented in Table 1 (the complete information, including reactions in $\mathrm{pH} 4,5$ and the chemical structure of the selected dyes are presented in the Supplementary Information (SI) section).

Good results were observed in Table 1 entries 3, 4 and 8 for the degradation of the RB198 and the RR195, both applying $\mathrm{pH} 3$. In general, the best results were observed when the reactions were carried out in $\mathrm{pH} 3$ and this in accordance with the higher initial activities usually presented for the tested enzymes in this $\mathrm{pH}$ (Table 1). It is known that the activity of peroxidases is significantly affected by the $\mathrm{pH}$ of the medium, and it is not uncommon a preference for acidic medium (usually in the range of $\mathrm{pH} 3$ ). This is due to the conformational changes in the active site of the enzymes. ${ }^{37}$ However, for the majority of DyPs there is a delicate balance between activity and stability based on the $\mathrm{pH}$ of the medium. Higher initial activities are observed in lower $\mathrm{pH}$, but the stability decreases under these conditions. ${ }^{12}$ The combination of these two factors may explain the reason why $\mathrm{pH} 3$ and 7 where the best $\mathrm{pH}$ systems, when compared to $\mathrm{pH} 4$ or 5.

Table 1. Results for the 30 min degradation reactions of different dyes applying SviDyP and TfuDyP and carried out in pH 3 or 7

\begin{tabular}{|c|c|c|c|c|c|c|}
\hline entry & Dye & Enzyme & $\mathrm{k}_{\mathrm{obs}}(\mathrm{pH} 3)^{\mathrm{a}} / \mathrm{s}^{-1}$ & $\mathrm{E}(\mathrm{pH} 3)^{\mathrm{a}, \mathrm{b}, \mathrm{c}} / \%$ & $\mathrm{k}_{\mathrm{obs}}(\mathrm{pH} 7)^{\mathrm{a}} / \mathrm{s}^{-1}$ & $\mathrm{E}(\mathrm{pH} 7)^{\mathrm{a}, \mathrm{b}, \mathrm{c}} / \%$ \\
\hline 1 & \multirow{2}{*}{ RG19 } & TfuDyp & $9.4 \times 10^{-3}$ & $43 \pm 0.8(0)$ & $6.6 \times 10^{-3}$ & $10 \pm 0(0)$ \\
\hline 2 & & SviDyP & $7.6 \times 10^{-3}$ & $67 \pm 2.4(0)$ & $2.6 \times 10^{-3}$ & $12 \pm 1.6(0)$ \\
\hline 3 & \multirow{2}{*}{ RB198 } & TfuDyp & $3.3 \times 10^{-3}$ & $100 \pm 0(0)$ & $8.1 \times 10^{-4}$ & $52 \pm 4.9(7)$ \\
\hline 4 & & SviDyP & $7.0 \times 10^{-4}$ & $100 \pm 0(0)$ & $4.0 \times 10^{-3}$ & $42 \pm 0.8(7)$ \\
\hline 5 & \multirow{2}{*}{ RB21 } & TfuDyp & $2.6 \times 10^{-3}$ & $25 \pm 4.1(23)$ & $3.7 \times 10^{-3}$ & $29 \pm 4.1(0)$ \\
\hline 6 & & SviDyP & $4.4 \times 10^{-3}$ & $55 \pm 1.6(23)$ & $3.7 \times 10^{-3}$ & $19 \pm 0.8(0)$ \\
\hline 7 & \multirow{2}{*}{ RR195 } & TfuDyp & $5.8 \times 10^{-3}$ & $69 \pm 3.3(0)$ & $3.5 \times 10^{-3}$ & $10 \pm 0.8(0)$ \\
\hline 8 & & SviDyP & $5.1 \times 10^{-3}$ & $100 \pm 0(0)$ & $1.1 \times 10^{-3}$ & $9 \pm 0(0)$ \\
\hline 9 & \multirow{2}{*}{ RY15 } & TfuDyp & $2.3 \times 10^{-2}$ & $37 \pm 3.3(0)$ & $2.2 \times 10^{-4}$ & $17 \pm 1.6(0)$ \\
\hline 10 & & SviDyP & $1.5 \times 10^{-3}$ & $39 \pm 0.8(0)$ & $3.7 \times 10^{-3}$ & $42 \pm 1.6(0)$ \\
\hline 11 & \multirow{2}{*}{ RY42 } & TfuDyp & $5.6 \times 10^{-3}$ & $6 \pm 1.6(0)$ & $3.9 \times 10^{-3}$ & $10 \pm 4.1(0)$ \\
\hline 12 & & SviDyP & $1.2 \times 10^{-3}$ & $0 \pm 0(0)$ & $7.2 \times 10^{-4}$ & $14 \pm 3.3(0)$ \\
\hline 13 & \multirow{2}{*}{ RR120 } & TfuDyp & $2.7 \times 10^{-3}$ & $3 \pm 0(0)$ & $5.8 \times 10^{-3}$ & $9 \pm 1.6(5)$ \\
\hline 14 & & SviDyP & $3.9 \times 10^{-2}$ & $59 \pm 0.4(0)$ & $1.4 \times 10^{-3}$ & $9 \pm 2.4(5)$ \\
\hline 15 & \multirow{2}{*}{ RB182 } & TfuDyp & $9.8 \times 10^{-3}$ & $31 \pm 0.2(0)$ & $2.6 \times 10^{-3}$ & $12 \pm 1.6(0)$ \\
\hline 16 & & SviDyP & $1.0 \times 10^{-2}$ & $38 \pm 2.4(0)$ & $4.4 \times 10^{-3}$ & $26 \pm 0.8(0)$ \\
\hline
\end{tabular}

aDye $\left(50 \mu \mathrm{mol} \mathrm{L}^{-1}\right), \mathrm{H}_{2} \mathrm{O}_{2}\left(100 \mu \mathrm{mol} \mathrm{L}{ }^{-1}\right)$, enzyme $\left(300 \mathrm{nmol} \mathrm{L}^{-1}\right), 50 \mathrm{mmol} \mathrm{L}^{-1}$ phosphate buffer $\mathrm{pH} 3$ or $50 \mathrm{mmol} \mathrm{L}^{-1}$ tris-HCl buffer $\mathrm{pH} 7$ (total volume $\left.=1 \mathrm{~mL}\right)$; ${ }^{\mathrm{b}}$ quoted results are the average based on the triplicate results and the standard deviation are shown; ${ }^{\mathrm{c}}$ percentage of $\mathrm{E}$ with $\mathrm{H}_{2} \mathrm{O}_{2}$ but without enzyme are given between parenthesis. $\mathrm{k}_{\mathrm{obs}}$ : initial activity; E: efficiency of degradation; RG19: Reactive Green 19; RB 198: Reactive Blue 198; RB21: Reactive Blue 21; RR195: Reactive Red 195; RY15: Reactive Yellow 15; RY42: Reactive Yellow 42; RR120: Reactive Red 120; RB182: Reactive Blue 182; TfuDyp and SviDyP: DyP peroxidases isolated from Thermobifida fusca (TfuDyp) and Saccharomonospora viridis, respectively. 
When applying $\mathrm{pH} \mathrm{3}$, in $30 \mathrm{~min}$ reactions, the performance of the enzyme SviDyP was better than the $T f u$ DyP. However, in general, decolorization was not perceptible in the 30 min reactions.

Giving that $\mathrm{pH} 3$ presented the best results, further tests were conducted in $2 \mathrm{~h}$ reactions applying the cited $\mathrm{pH}$ system. In the experiments performed during $2 \mathrm{~h}$ the observed efficiency of degradation was, sometimes, lower than the observed results in Table 1. This result could be explained by the fact that some products of degradation produce a similar absorption spectrum leading to the false sense of smaller degradation. ${ }^{12}$ The decolorization process was also not perceptible in these tests.

Taking into consideration the dubious results observed in the $2 \mathrm{~h}$ reactions, the reaction times were expanded to $12 \mathrm{~h}$. For such kind of experiments, the stability of the enzymes had to be taken into account. In general, DyP-type peroxidases have higher activity at lower $\mathrm{pH}$, but their stability is lower in these conditions. ${ }^{1}$ Another important observation is that inactivation occurs when in the presence of a high amount of hydrogen peroxide. With these considerations in mind, the reactions started with $300 \mathrm{nmol} \mathrm{L}^{-1}$ of the enzyme and with $0.2 \mathrm{mmol} \mathrm{L}^{-1}$ of $\mathrm{H}_{2} \mathrm{O}_{2}$ and at $4 \mathrm{~h}$ intervals additional enzyme and $\mathrm{H}_{2} \mathrm{O}_{2}$ were added in the reactions. ${ }^{38}$

For this new set of experiments twelve reactive dyes were tested: the previous eight and additional four (the chemical structure of all selected dyes can be found in the SI section). The results in terms of $\mathrm{E}(\%)$ for these reactions can be observed in Table 2 and Table S4 (SI section). This new protocol was able to provide decolorization for the majority of the tested dyes. Photos exhibiting the decolorization results are also presented in Table 2 and Table S4 (SI section).

Some really interesting results in terms of degradation can be observed in Table 2. In most cases, when comparing the decolorization in the control reaction with the reaction applying SviDyP there is a considerable visual difference. The enzyme SviDyP presented pronounced decolorization and degradation results.

Appealing results were also observed for the reactions applying RG19, RB182 and RR120 in the presence of SviDyP, with E $=100,86$ and $83 \%$, respectively, and visible decolorization (Table 2, entries 3, 6 and 12). For the RR195, RB5, RB198, and RB171, the degradation was smaller, but still high $(\mathrm{E}=64-78 \%$, Table 2 entries 9, 15 and 18 and Table S4 (SI section) entry 12, respectively) in the presence of $S v i \mathrm{DyP}$ and decolorization was also observed.

From the results in Table 2, it is possible to note that the best results in $12 \mathrm{~h}$ reactions with the majority of the tested dyes were obtained in the presence of the enzyme SviDyP
Table 2. Results for the $12 \mathrm{~h}$ degradation reactions of different dyes applying $S v i \mathrm{DyP}$ and TfuDyP and carried out in $\mathrm{pH} 3$

\begin{tabular}{|c|c|c|c|c|c|}
\hline entry & Dye & Enzyme & $\mathrm{E}(\mathrm{pH} 3)^{\mathrm{a}, \mathrm{b}} / \%$ & $\begin{array}{c}\text { Initial } \\
\text { solution } \\
\text { of dye }\end{array}$ & $\begin{array}{l}\text { Solution of the } \\
\text { dye after } 12 \mathrm{~h}^{\mathrm{d}}\end{array}$ \\
\hline 1 & & control $^{\mathrm{c}}$ & $3 \pm 0.8(5)$ & & \\
\hline 2 & RG19 & TfuDyP & $17 \pm 5.7(5)$ & & \\
\hline 3 & & SviDyP & $100 \pm 0(5)$ & & \\
\hline 4 & & control $^{\mathrm{c}}$ & $0 \pm 0(6)$ & & \\
\hline 5 & RB182 & TfuDyP & $38 \pm 6.5(6)$ & & \\
\hline 6 & & $S v i \mathrm{DyP}$ & $86 \pm 3.2(6)$ & & \\
\hline 7 & & control $^{\mathrm{c}}$ & $2 \pm 0.8(3)$ & & \\
\hline 8 & RR195 & TfuDyP & $6 \pm 0(3)$ & & \\
\hline 9 & & $S v i \mathrm{DyP}$ & $68 \pm 5.7(3)$ & & \\
\hline 10 & & control $^{\mathrm{c}}$ & $0 \pm 0(8)$ & & \\
\hline 11 & RR120 & TfuDyP & $24 \pm 0.8(8)$ & & \\
\hline 12 & & SviDyP & $83 \pm 2.4(8)$ & & \\
\hline 13 & & control $^{\mathrm{c}}$ & $0 \pm 0(0)$ & 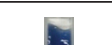 & \\
\hline 14 & RB5 & $T f u \mathrm{DyP}$ & $0 \pm 0(0)$ & & \\
\hline 15 & & SviDyP & $66 \pm 0.8(0)$ & & \\
\hline 16 & & control $^{\mathrm{c}}$ & $0 \pm 0(10)$ & & \\
\hline 17 & RB198 & TfuDyP & $76 \pm 2.5(10)$ & & \\
\hline 18 & & SviDyP & $78 \pm 6.5(10)$ & - & \\
\hline
\end{tabular}

${ }^{\text {a Dye }}\left(50 \mu \mathrm{mol} \mathrm{L} \mathrm{L}^{-1}\right), \mathrm{H}_{2} \mathrm{O}_{2}(100 \mu \mathrm{mol} \mathrm{L}-1)$, enzyme $\left(300 \mathrm{nmol} \mathrm{L}^{-1}\right)$, phosphate buffer $\mathrm{pH}$ (total volume $=1 \mathrm{~mL}$ ). At $4 \mathrm{~h}$ intervals, and over a total reaction time of $12 \mathrm{~h}$, additional enzyme $\left(0.05 \mathrm{nmol} \mathrm{L}^{-1}\right)$ and $\mathrm{H}_{2} \mathrm{O}_{2}$ $\left(0.2 \mathrm{mmol} \mathrm{L}^{-1}\right)$ were added to the reaction mixture. Percentage of $\mathrm{E}$ with $\mathrm{H}_{2} \mathrm{O}_{2}$, but without enzyme are given between parenthesis; ${ }^{\mathrm{b}}$ quoted results are the average based on the triplicate results and the standard deviation are shown; 'dye $\left(50 \mu \mathrm{mol} \mathrm{L}^{-1}\right), 50 \mathrm{mmol} \mathrm{L}^{-1}$ phosphate buffer $\mathrm{pH} 3$ (total volume $=1 \mathrm{~mL}$ ); ${ }^{\mathrm{d}}$ the pictures show first the control reaction without enzyme; second, the reaction applying TfuDyP; and third, the reaction applying SviDyP. E: efficiency of degradation; RG19: Reactive Green 19; RB182: Reactive Blue 182; RR195: Reactive Red 195; RR120: Reactive Red 120; RB5: Reactive Black 5; RB 198: Reactive Blue 198; TfuDyp and SviDyP: DyP peroxidases isolated from Thermobifida fusca (TfuDyp) and Saccharomonospora viridis, respectively.

(except for dye Reactive Blue 21 when degradation using $T f u$ DyP was $88 \%$, Table S4, SI section, entries 2 and 3). The performance difference of these enzymes for $12 \mathrm{~h}$ reactions can be related to the good stability of the SviDyP, which stays active for longer periods of time during the reactions.

\section{Electrochemical assays}

\section{Cyclic voltammetry of reactive dyes}

When observing the reactivity of the enzymes towards the tested reactive dyes, it is in principle not clear why some substrates were degraded faster than others. The cyclic voltammetry can help in this elucidation.

Cyclic voltammograms of the dyes (Figures S2-S8, SI section) show three major groups of electrochemical 
processes, as illustrated in the Figure 1, taking into account the potential window under study. In the positive scan, an irreversible process was observed for all of the evaluated dyes. In the negative scan, it was observed an irreversible reduction process, and in some cases, at more negative potentials, a second cathodic peak appears due to chlorotriazine reduction. The third process refers to a semi-reversible redox peak couple, associated with the formation of an unstable amine. ${ }^{18}$

The more negative and positive redox peaks could be associated with irreversible redox reactions leading to cleavage of the azo bonds. The presence of more than one azo group in the dye structure causes an increase in the complexity of the voltammogram due to the appearance of multiple electrochemical processes. These peaks are the result of the oxidation of the amine products generated during the rupture of more than one azo bond. ${ }^{18}$

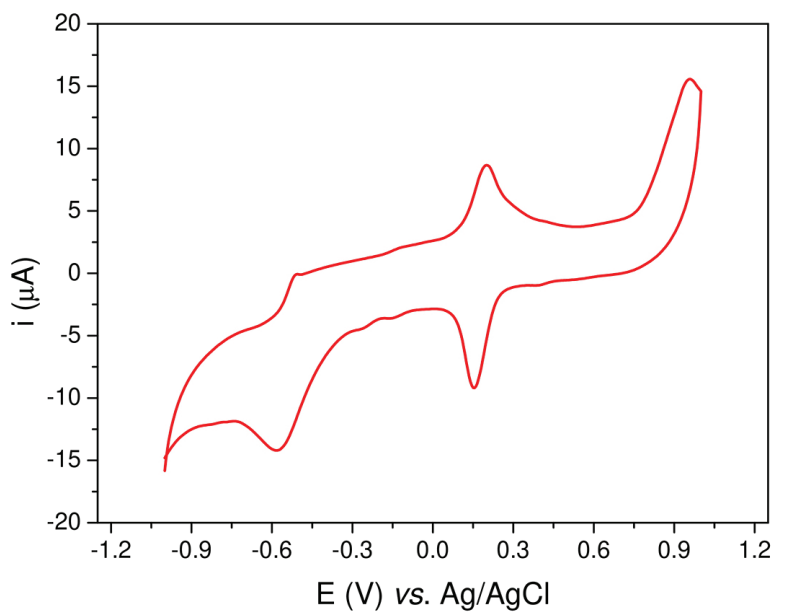

Figure 1. Cyclic voltammograms of Reactive Red 120 (RR120) in BrittonRobinson buffer solution $\left(0.12 \mathrm{~mol} \mathrm{~L}^{-1}, \mathrm{pH} 3.0\right)$ at scan rate of $0.05 \mathrm{~V} \mathrm{~s}^{-1}$.

\section{Redox potential pH dependence}

In addition to the structure of the dye itself, the ability of enzymes in degrading dyes depends on the $\mathrm{pH}$ of the medium and on the difference between the redox potential (oxidation) of the biocatalyst and the dye. ${ }^{18}$

The dyes RB21, RB182, RB198, RR120, RR195, RY42 and RG19 were further analyzed due to the highest percentages of degradation and decolorization observed after the treatment with the enzymes. The overall observation (example in Figure 2) is that most of the dyes show $\mathrm{pH}$ dependent peaks, with $\mathrm{E}_{\mathrm{p}}$ (peak potential) decreasing as the $\mathrm{pH}$ increases from 3.0 to 9.0 then becoming constant from 9.0 to 11.0 (Figures S2-S8, SI section). The exceptions are RY42 and RB21, which only exhibited $\mathrm{pH}$ dependence in the acid range (respectively, Figures S7 and S8, SI section).

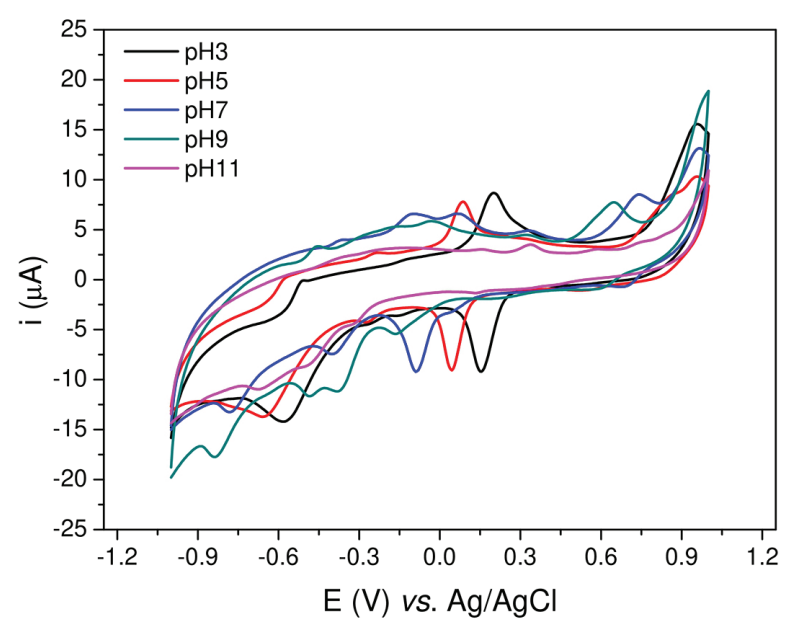

Figure 2. Cyclic voltammograms of Reactive Red 120 (RR120) in BrittonRobinson buffer solution $\left(0.12 \mathrm{~mol} \mathrm{~L}^{-1}\right)$, $\mathrm{pH}$ range from 3.0 to 11.0 , at scan rate of $0.05 \mathrm{~V} \mathrm{~s}^{-1}$.

\section{Redox potential and degradation}

The goal of this study was to find a correlation between the enzymes redox potential and the range of oxidizable dyes. The redox potential is a preliminary tool to predict the degradation capacity of oxidative biocatalysts. ${ }^{18}$ The redox potential values were determined individually for each one of the different dyes (Figures S2-S8, SI section). In addition to the redox potentials of the dyes, the redox potential of the studied DyPs were measured (Figures S9 and S10, SI section). The relative redox potential values of the DyPs were: $0.065 \mathrm{~V} v s . \mathrm{Ag} / \mathrm{AgCl}(\mathrm{pH} \mathrm{3.0)}$ ) and $0.065 \mathrm{~V}$ vs. $\mathrm{Ag} / \mathrm{AgCl}(\mathrm{pH} 7.0)$ applying $T f u \mathrm{DyP}$ and $0.214 \mathrm{~V}$ vs. $\mathrm{Ag} / \mathrm{AgCl}(\mathrm{pH} \mathrm{3.0)}$ ) applying SviDyP. In the experiments carried out using $\mathrm{pH} 7.0$ the redox potential was not detected when the enzyme was $S v i$ DyP.

The majority of the azo dyes tested presented one or more apparently irreversible peak in the positive scan (Figures S2-S8, SI section). According to the literature, ${ }^{18,19}$ that process may be attributed to the cleavage of the azo bond. The oxidation processes are more relevant due the fact that the enzymatic DyP degradation process is an oxidative mechanism. Regarding this, an increase in the redox potential of the substrate should consequently decrease the efficiency of the degradation. ${ }^{18}$ Hence, when crossing these redox potentials with the degradation efficiency data of reactions applying SviDyP, a reasonable relationship was found. It was observed that the higher the redox potential, the lower was the observed degradation efficiency of the SviDyP. On the other hand, TfuDyP data showed a higher discrepancy between the compounds. These observations suggest that the difference in redox potential between the metal center and the substrate is an important factor contributing to substrate oxidation. Therefore, it is expected that the driving force for a redox 
reaction is proportional to the potential difference between oxidant and reducer, which could explain the inversion of the magnitude of the degradation of some dyes between the two enzymes studied. ${ }^{18}$

\section{Genotoxicity of the bioproducts}

The products of the decolorization reactions were not characterized. In this case, it is more important to understand the toxicity of the products then to elucidate their structure. Some of the treated solutions from Table 2 were selected for experiments regarding the genotoxicity and compared with control reactions (reactions with $\mathrm{H}_{2} \mathrm{O}_{2}$ but without enzyme). The selected reactions presented good degradation efficiency and clear decolorization (Tables 2 and S4, SI section).

The combination of DNA with the electrochemical transducer produces a type of affinity biosensor capable of quickly recognizing and monitoring organic DNA-binding compounds, which can cause DNA damage. ${ }^{28}$ This method was chosen due to its simplicity and because it does not require special reagents or modifications in the DNA structure. The operating principle of the device is based on the biomolecular recognition of specific DNA binding processes, employing an electrochemical signal from a redox probe as an analytical response.

By evaluating the electrochemical response of the probe, we can detect a possible damage to the DNA, mainly due to the displacement of the potential of the processes. When there is a connection of the analyte to the DNA by intercalation between the stacked base pairs of double stranded DNA (dsDNA), a shift in the positive direction of the probe's peak potential is observed, while if there is an interaction with DNA by electrostatic attraction (interaction with the negative charge of the sugar-phosphate nucleic structure), a shift is observed in the negative direction of the probe's peak potential. ${ }^{28}$ In addition to the effects caused on the potential, peak currents can also assist in the investigation of processes, since their values can be modified by the interaction of other molecules competing with the redox probe.

By comparing the results from the control reaction (samples with lower degree of degradation and decolorization) and the biodegraded dyes, usually the latter shows a lower degree of interaction with DNA. Only the experiments using dyes RG19 (Table 2, entry 3) and RR120 (Table 2, entry 12) showed a higher degree of interaction in the biodegraded samples, and only in the sample using RR120 this interaction was more pronounced.

The samples from the reactions using the dyes RB21 and RY42 showed low levels of interaction (ca. 5\%), presenting a low genotoxicity from control reactions (RB21 and RY42, Table S4, SI section, entries 1 and 7, respectively) and products of biodegradation (RB21 and RY42, Table S4, SI section, entries 2 and 9, respectively). The control reaction using RR195, on the other hand, presented a high degree of interaction with the genosensor surface (RR195, Table 2, entry 7) and practically non-existent interaction for RR195 biodegraded products (Table 2, entry 9), showing an impressive apparent reduction of genotoxicity. The control reactions using dyes RB182 (Table 2, entry 4) and RB198 (Table 2, entry 16) presented significant levels of interaction with the genosensor surface. However, both biodegraded samples RB182 (Table 2, entry 6) and RB198 (Table 2, entry 18) showed a lower level of genotoxicity.

In addition, the potential shift of the redox probe was analyzed in the presence of the control samples and the samples of biodegraded dyes. In the control samples RB182 (Table 2, entry 4), RB21 (Table S4, SI section, entry 1) and RR120 (Table 2, entry 10), a positive shift of the probe potential was observed, which suggests an interaction of the sample with the genosensor surface. This behavior is exemplified in Figure 3A by Reactive Blue 182. After the enzymatic treatment, this interaction was practically non-existent in sample RB21 (Table 2, entry 17), less pronounced in sample RB182 (Table 2, entry 6), and remained quite pronounced in sample RR120 (Table 2, entry 12). This behavior was similar to that observed by the analysis of the voltammetric current response of the probe.

In control samples RB198 (Table 2, entry 16), RG19 (Table 2, entry 1), RR195 (Table 2, entry 7) and RY42 (Table S4, SI section, entry 7), it was observed a negative shift in the redox potential of the probe which suggest that after interaction with the dye there is a decrease in the intercalation of the probe, due to an interaction on genosensor surface with the sample dye. However, applying the biodegraded samples, this potential shift was practically non-existent, suggesting a lower genoxicity of the samples after the enzymatic treatment. This behavior is exemplified in Figure 3B by Reactive Red 195.

Some of the voltammograms from the bioproducts showed an unexpected increase on the intensity of the probe's signal (example in Figure 3A). In order to investigate this behavior in detail, a complementary spectrophotometric study was carried out applying only the biodegraded reactions. The spectrophotometric data of test I (DNA and biodegraded sample), demonstrated that some of the chosen samples in fact can still have interaction with the DNA (example in Figure 4), although most of the time in lower extension. This interaction is shown by the hyperchromic behavior, which can be related to breaking of the phosphodiester bond of DNA. ${ }^{39,40}$ When observing 

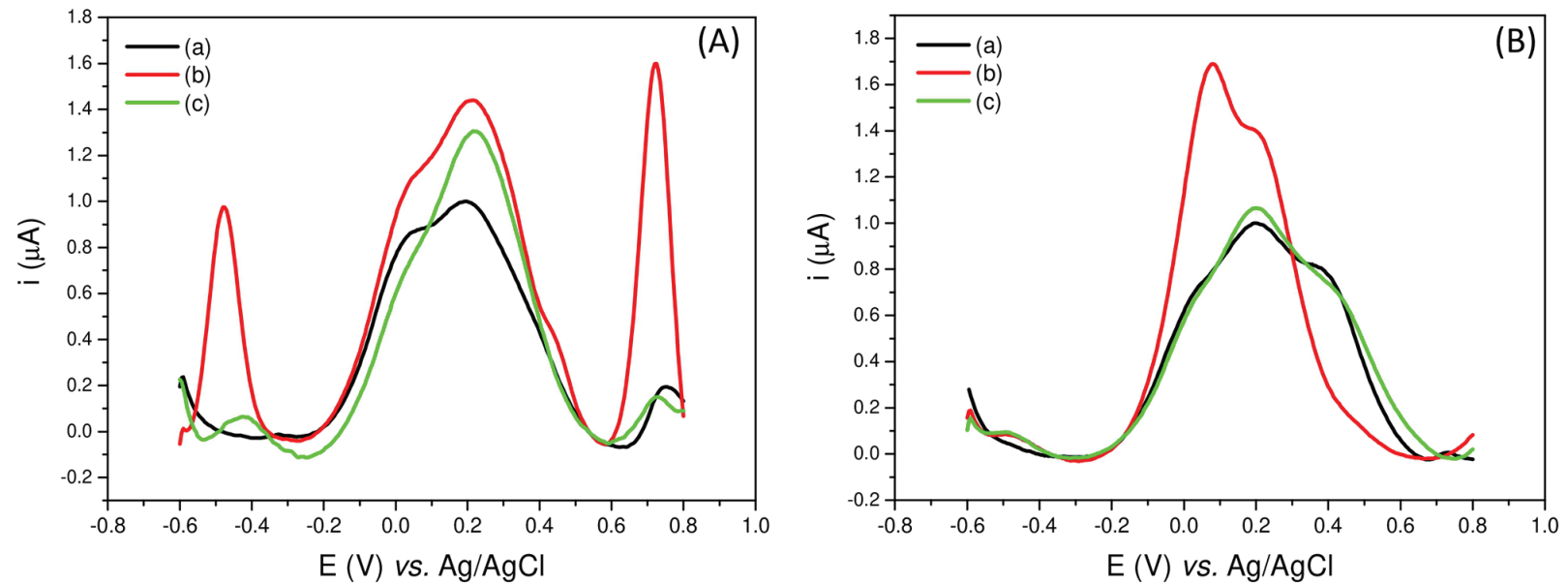

Figure 3. (A) SWV of the genosensor containing (a) the base peak (Reactive Black 5, RB5, probe), (b) the peak after the interaction with control sample of Reactive Blue 182 (RB182, Table 2, entry 4), (c) the peak after the interaction with the bioproducts of Reactive Blue 182 (RB182, Table 2, entry 6). (B) SWV of the genosensor containing (a) the base peak (Reactive Black 5, RB5, probe), (b) the peak after the interaction with control sample of Reactive Red 195 (RR195, Table 2, entry 7), (c) the peak after the interaction with the bioproducts of Reactive Red 195 (RR195, Table 2, entry 9). Measured at frequency of $90 \mathrm{~Hz}$, amplitude of $60 \mathrm{mV}$ and potential increment of $5 \mathrm{mV}$.

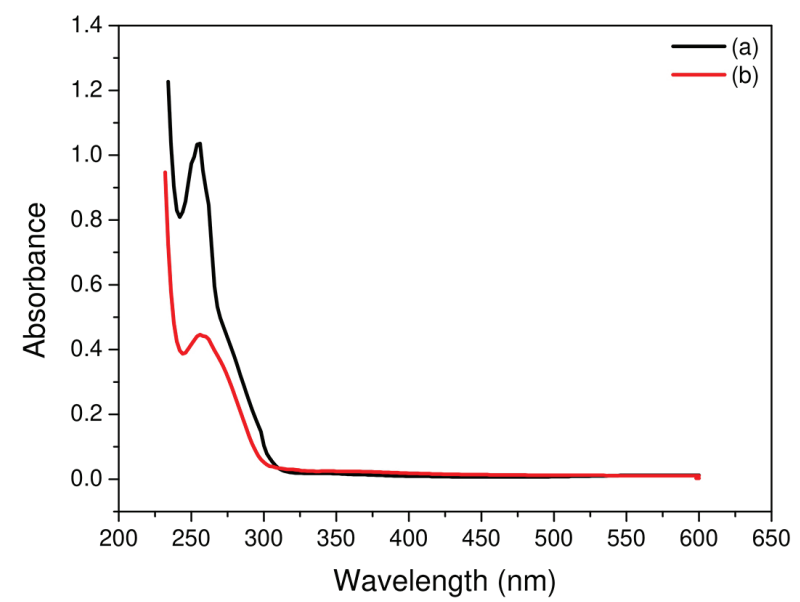

Figure 4. Test I applying the bioproducts of Reactive Blue 198 (RB198, Table 2, entry 18), where (a) is the mixture between sample and DNA, and (b) is pure DNA.

the interaction between DNA and the electrochemical probe (test II), it exhibited a hypochromic effect (data not shown), that suggests an intercalation with $\mathrm{DNA}^{40}$ and is consistent with its planar structure. This observation is also in accordance with the obtained electrochemical data since assembling the probe's layer showed consistency throughout the assay.

Finally, test III, which simulates the complete electrochemical system (DNA + redox probe + biodegraded products), presented lower observed absorbance (for all samples) than test I (example in Figure 5), but in some cases higher values than test II. These results suggest that for these samples a higher interaction with DNA than the chosen probe (Reactive Black 5) is present. This result may explain the electrochemical data, supposing that the samples are able to replace the probe on the DNA, thus

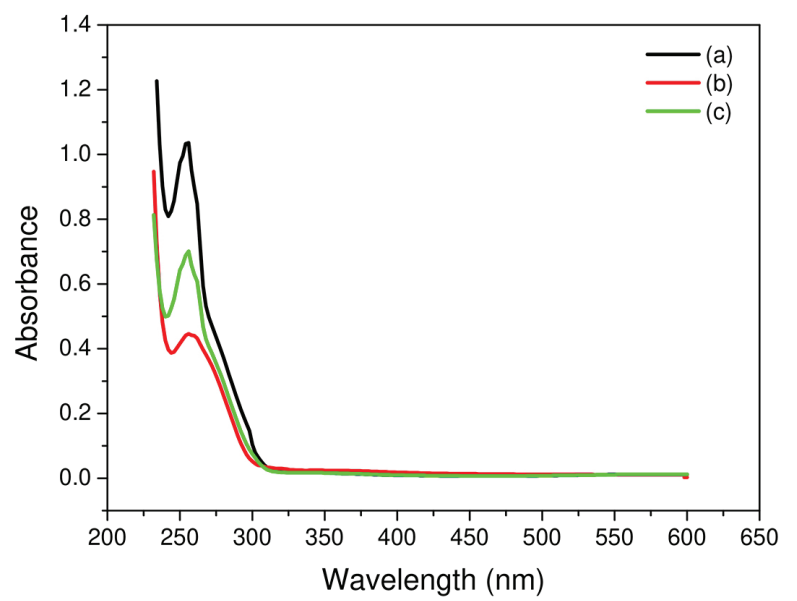

Figure 5. Spectra of assays (test III) applying the biodegraded products from Reactive Blue 198 (RB198, Table 2, entry 18), where (a) is the interaction between Reactive Black 5 (RB5, probe), DNA and the sample, (b) is pure DNA and (c) is the interaction between DNA and sample.

exposing the probe on the electrode's surface and increasing the level of current.

\section{Conclusions}

The DyP-Type peroxidases, TfuDyP and SviDyP, presented a great biocatalytic potential for the degradation and decolorization of the tested reactive dyes. Most of the time, the enzyme SviDyP showed better results when compared to the same condition applying TfuDyP. Among the tested $\mathrm{pH}$ systems, $\mathrm{pH} 3$ led to the best results for the majority of the reactions. For the $30 \mathrm{~min}$ reactions carried out in $\mathrm{pH} \mathrm{3}$, good degradation efficiency was observed, despite no decolorization. For the $12 \mathrm{~h}$ reactions, both great degradation efficiency and decolorization were observed when SviDyP was applied. The electrochemical 
tests employing voltammetry, regarding the obtention of the redox potentials of the dyes and enzymes, were an important tool to explain the degradation capacity of the enzymes. For the series of dyes studied, a good correlation was observed between the degradation efficiency of SviDyP and the data of redox potential.

Analysis using the electrochemical genosensor combined with the spectrophotometric method showed that the dye degradation bioproducts mostly presented a lower degree of genotoxicity when compared to the control reactions (without enzymes). This was evaluated by the variation of the analytical probe signal used. Only the dyes RR120 and RG19 presented a higher degree of interaction with the surface of the genosensor after the enzymatic treatment of the samples, when compared to the control samples.

\section{Supplementary Information}

Supplementary information is available free of charge at http://jbcs.sbq.org.br as PDF file.

\section{Acknowledgments}

The authors would like to thank Prof Marco W. Fraaije (University of Groningen, The Netherlands) for kindly donating the DyP enzymes. C. S. acknowledges support from CNPq PIBIC fellowship.

\section{References}

1. Ogola, H. J. O.; Ashida, H.; Ishikawa, T.; Sawa, Y. In Advances in Bioremediation of Wastewater and Polluted Soil; Shiomi, N., ed.; IntechOpen, 2015, p. 111-144.

2. Cristóvão, R. O.; Tavares, A. P. M.; Loureiro, J. M.; Boaventura, R. A. R.; Macedo, E. A.; Environ. Technol. 2008, 29, 1357.

3. Petrović, M. M.; Mitrović, J. Z.; Antonijević, M. D.; Matović, B.; Bojić, D. V.; Bojić, A. L.; Mater. Chem. Phys. 2015, 158, 31.

4. Lam, F. L. Y.; Hu, X.; Lee, T. M. H.; Chan, K. Y.; Sep. Purif. Technol. 2009, 67, 233.

5. Gunasekar, V.; Ponnusami, V.; J. Sol-Gel Sci. Technol. 2015, 74,84 .

6. Mohan, S. V.; Prasad, K. K.; Rao, N. C.; Sarma, P. N.; Chemosphere 2005, 58, 1097.

7. de Souza, S. M. A. G. U.; Forgiarini, E.; de Souza, A. A. U.; J. Hazard. Mater. 2007, 147, 1073.

8. Legerská, B.; Chmelová, D.; Ondrejovič, M.; Nova Biotechnol. Chim. 2016, 15, 90.

9. Kim, G. Y.; Lee, K. B.; Cho, S. H.; Shim, J.; Moon, S. H.; J. Hazard. Mater. 2005, 126, 183.
10. Terres, J.; Battisti, R.; Andreaus, J.; de Jesus, P. C.; Biocatal. Biotransform. 2014, 32, 64.

11. Fraaije, M. W.; van Bloois, E.; Enzyme Eng. 2012, 1, DOI: 10.4172/2329-6674.1000e105.

12. Lončar, N.; Colpa, D. I.; Fraaije, M. W.; Tetrahedron 2016, 72, 7276.

13. Chen, C.; Shrestha, R.; Jia, K.; Gao, P. F.; Geisbrecht, B. V.; Bossmann, S. H.; Shi, J.; Li, P.; J. Biol. Chem. 2015, $290,23447$.

14. Brissos, V.; Tavares, D.; Sousa, A. C.; Robalo, M. P.; Martins, L. O.; ACS Catal. 2017, 7, 3454.

15. Shrestha, R.; Huang, G.; Meekins, D. A.; Geisbrecht, B. V.; Li, P.; ACS Catal. 2017, 7, 6352.

16. Yu, W.; Liu, W.; Huang, H.; Zheng, F.; Wang, X.; Wu, Y.; Li, K.; Xie, X.; Jin, Y.; PLoS One 2014, 9, e110319.

17. Osugi, M. E.; Carneiro, P. A.; Zanoni, M. V. B.; J. Braz. Chem. Soc. 2003, 14, 660.

18. Zille, A.; Ramalho, P.; Tzanov, T.; Millward, R.; Aires, V.; Cardoso, M. H.; Ramalho, M. T.; Gu, G. M.; Cavaco-paulo, A.; Biotechnol. Prog. 2004, 2, 1588.

19. Kariyajjanavar, P.; Narayana, J.; Nayaka, Y. A.; Umanaik, M.; Electrochim. Acta 2010, 28, 265.

20. Shetti, N. P.; Malode, S. J.; Malladi, R. S.; Nargund, S. L.; Shukla, S. S.; Aminabhavi, T. M.; Microchem. J. 2019, 146, 387.

21. Rocha, C. G.; Ferreira, A. A. P.; Yamanaka, H.; Sens. Actuators, B 2016, 236, 52.

22. Beldean-Galea, M. S.; Copaciu, F. M.; Coman, M. V.; J. AOAC Int. 2018, 101, 1353.

23. Andleeb, S.; Atiq, N.; Parmar, A.; Robson, G. D.; Ahmed, S.; Environ. Monit. Assess. 2011, 176, 597.

24. Peláez-Cid, A. A.; Blasco-Sancho, S.; Matysik, F. M.; Talanta 2008, 75, 1362.

25. Dossi, N.; Toniolo, R.; Pizzariello, A.; Susmel, S.; Perennes, F.; Bontempelli, G.; J. Electroanal. Chem. 2007, 601, 1.

26. Dong, Y.; Zhang, J.; Xing, Y.; Song, Z.; Wang, Y.; Meng, M.; Deng, C.; Tong, Z.; Yin, Y.; Xi, R.; J. Agric. Food Chem. 2015, 63, 6338 .

27. Hudari, F. F.; Brugnera, M. F.; Zanoni, M. V. B. In Applications of the Voltammetry; Stoytcheva, M.; Zlatev, R., eds.; IntechOpen, 2017, p. 75-108.

28. Vyskočil, V.; Blašková, M.; Hájková, A.; Horáková, E.; Krejčová, Z.; Stávková, K.; Wang, J.; Sisensing Electroanal. 2012, 7, 141.

29. Radi, A. E.; Nassef, H. M.; El-Basiony, A.; Dyes Pigm. 2013, 99, 924.

30. Ghalwa, N. A.; IEEE Sens. J. 2013, 13, 4757.

31. Yang, J.; da Rocha, C. G.; Wang, S.; Ferreira, A. A. P.; Yamanaka, H.; Talanta 2015, 142, 183.

32. Manzanares-Palenzuela, C. L.; Martín-Fernández, B.; López, M. S.-P.; López-Ruiz, B.; TrAC, Trends Anal. Chem. 2015, 66, 19.

33. Hudari, F. F.; Costa Ferreira, S. L.; Zanoni, M. V. B.; Electroanalysis 2016, 28, 1085. 
34. Viana, E. R. C.; Pereira, F. C.; Zanoni, M. V. B.; Dyes Pigm. 2006, 71, 145.

35. Hudari, F. F.; de Almeida, L. C.; da Silva, B. F.; Zanoni, M. V. B.; Microchem. J. 2014, 116, 261.

36. Ming, L.; Xi, X.; Chen, T.; Liu, J.; Sensors 2008, 8, 1890.

37. Kalsoom, U.; Bhatti, H. N.; Asgher, M.; Appl. Biochem. Biotechnol. 2015, 176, 1529.
38. Liers, C.; Bobeth, C.; Pecyna, M.; Ullrich, R.; Hofrichter, M.; Appl. Microbiol. Biotechnol. 2010, 85, 1869.

39. Uliana, C. V.; Garbellini, G. S.; Yamanaka, H.; J. Braz. Chem. Soc. 2012, 23, 1469.

40. Biver, T.; Secco, F.; Tinè, M. R.; Venturini, M.; Bencini, A.; Bianchi, A.; Giorgi, C.; J. Inorg. Biochem. 2004, 98, 1531.

Submitted: November 16, 2020 Published online: February 25, 2021 